\title{
JUICIO DE ACUSACIÓN, IMPARCIALIDAD DEL ACUSADOR Y DERECHO DE DEFENSA*
}

Teresa Armenta Deu**

\begin{abstract}
RESUMEN
En unión de la tendencia a garantizar la imparcialidad judicial, encomendando la investigación de los delitos al fiscal, surgen dos cuestiones importantes: a) cómo se garantiza la imparcialidad del órgano acusador a la hora de efectuar el juicio de acusación; y b) las dificultades de la defensa para ejercitar sus derechos en el seno de dicho juicio de acusación. Ilustran estos temas, sendas referencias al proceso penal anglosajón y norteamericano; dos modelos internacionales, como son la CPI y los proyectos de la UE (Libro Verde y Corpus Iuris); y dos ejemplos de ordenamientos europeos, objetos de sendas reformas: Italia y España.
\end{abstract}

\section{PALABRAS CLAVES}

Acusación, acusatorio, adversarial, imparcialidad, derecho de defensa.

\begin{abstract}
Together with the tendency to guarantee the juridical objectivity; commending the investigation of offences to the public prosecutor, two important issues arise: a) How the objectivity of the prosecuting organ is guaranteed at the time of_executing the prosecution trial.
\end{abstract}

Este trabajo ha sido realizado disfrutando del I+D "Internacionalización de la Justicia y reforma del proceso penal" (Ref. SEJ2004-00266); así como con una "Ayuda a la Investigación” de la Generalitat de Catalunya, (SGR, 00086). Este artículo fue recibido el 3 de octubre, siendo aprobada su publicación con fecha 20 de noviembre de 2007.

** La autora es catedrática de Derecho Procesal de la Universidad de Girona (España). E-mail: tarmenta@uoc.edu.
} 
b) The difficulties of the defense to practice its rights in the frame of such_prosecution trial.

Important references to the North American and Anglo-Saxon legal process illustrate this topic; two international models such as the CPI and the EU projects (Green Book and Corpus Iuris); and two examples of European ordinances, object of important reforms: Italy and Spain.

\section{KEY WORDS:}

Prosecution, prosecuting, adversarial, objectivity, right to the defense.

\section{Planteamiento y delimitación del tema}

Referirse al calificativo acusatorio abre tal cúmulo de cuestiones que resulta inexcusable delimitar en primer lugar el objetivo de estas líneas. La constante apelación al sistema acusatorio como modelo de referencia obligada en las diferentes reformas del proceso penal ha servido para propiciar un importante número de estudios que a su vez han permitido dibujar sus contornos con mayor precisión, romper la equivalencia acusatorio-adversarial; y depurar su concepto con mayor o menor acierto ${ }^{1}$. Hoy por hoy parecen más claras las líneas que delimitan un modelo adversarial o de partes y otro acusatorio; el principio acusatorio en relación con otros principios y derechos como el de contradicción y defensa; e incluso se admite que la esencialidad del acusatorio no exige que instruya el fiscal ${ }^{2}$. A partir de estas consideraciones y como el título permite adelantar, quiero centrar mi análisis en determinados aspectos que conciernen al conocido como juicio de acusación y su formación ${ }^{3}$. O por mejor expresarlo, desearía poner sobre el tapete una serie de reflexiones en torno a dos aspectos singulares en conexión con dicho tema:

1 Entre otros muchos, por orden alfabético, destacan por contribuir a tal delimitación: ARMENTA DEU, T, "Principio acusatorio y derecho penal", Bosch, Barcelona, 1995; ASENCIO MELLADO, "Principio acusatorio y derecho de defensa en el proceso penal", Trivium, $1^{\text {a }}$ ed, Madrid, 1991; GUERRERO PALOMARES, S, "El principio acusatorio", Aranzadi, 2005, p. 88ss; GOMEZ COLOMER, J.L, "La investigación criminal: problemas actuales y perspectivas de unificación internacional”, RPJud, n.64, 4 trim 2001, p.4ss.; MONTERO AROCA, J, "La garantía procesal penal y el principio acusatorio", Revista la Ley, 1994-1, y "El principio acusatorio. Un intento de aclaración conceptual”, Revista Justicia, IV/1992; y VERGER GRAU, "La defensa del imputado y el principio acusatorio", Bosch, Barcelona, 1994. Valgan, además, las citas que se irán haciendo a lo largo de este trabajo.

2 Hasta los más firmes partidarios de la instrucción por el fiscal admiten que cabe garantizar plenamente la vigencia del principio acusatorio en sistemas de instrucción judicial en los que -como en el ordenamiento español- la función de enjuiciar esté netamente separada de la función de investigación, FUENTES SORIANO, $\mathrm{O}$, "La investigación por el fiscal en el proceso penal abreviado y en los juicios rápidos", Tirant monografías, Valencia, 2005, p. 244.

3 Su propia denominación "juicio de acusación" se ha extendido a partir de la STC 186/1990 en la que, para sostener una finalidad de la fase intermedia diferente a la del procedimiento ordinario, se atribuía a aquella elaborar el juicio de acusación, y no cerrar la instrucción, como se pormenorizará después. 
Juicio de acusación, imparcialidad del acusador

y derecho de defensa

la imparcialidad del acusador, y la posición del imputado y su derecho de defensa en el periodo intermedio ${ }^{4}$.

La elección trae causa de una mirada general al ámbito internacional y a las reformas más recientes de la ley de enjuiciamiento criminal, aunque también a las de otros ordenamientos de nuestro ámbito socio-jurídico. La tremenda influencia de los EEUU de Norteamérica en los diferentes países pero asimismo en órganos internacionales como la CPI; la perspectiva en ocasiones acrítica cuando no mitificada con la que se mira el proceso "acusatorio puro"s; y las no tan recientes reformas de la LECrim merecen una reflexión conjunta que propicie extraer conclusiones ponderadas y útiles, si como vuelve a anunciarse la Ley de Enjuiciamiento Criminal será objeto de próxima reforma.

Como es sobradamente conocido, entre las dos fases tradicionalmente reconocidas en el proceso penal, instructora o de investigación y de enjuiciamiento propiamente dicho, cabe añadir una tercera de juicio específico sobre la existencia de acción penal, encaminada, de un lado, a entender bien cerrada la primera, y de otro, a valorar positivamente la apertura de la fase de juicio (fase intermedia o juicio de acusación) ${ }^{6}$. Al margen de su denominación, se reconozca o no su independencia en el conjunto de juicios que tienen lugar a lo largo del proceso y se perciba o no una finalidad específica en cada uno de los procesos, este juicio de acusación resulta imprescindible para salvaguardar el principio acusatorio, de manera que su concurrencia más o menos independiente resulta ineludible.

Por otra parte, aunque sin apartar la mirada de este ámbito, la constante interinfluencia entre los sistemas procesales penales en los países pertenecientes al "common law" o al "civil

Quiero significar así que eludiré aquellos otros que tienen lugar en el proceso una vez que la acusación se ha ejercitado: la correlación entre acusación y sentencia y la prohibición de "reformatio in peius"; así como la iniciativa probatoria del juez en el juicio oral. El foco de atención será un análisis comparativo del juicio de acusación, los sujetos a quien se encomienda, su imparcialidad y quien controla aquél. Hace ya algunos años, analicé el principio acusatorio en dos trabajos centrándome en los aspectos que precisamente ahora desecho: Principio acusatorio y derecho penal; Bosch, Barcelona; y "Principio acusatorio: realidad y utilización lo que es y lo que no, R. Derecho Procesal, 1996, n.2; p. 265ss.

5 Convendremos en esta denominación ("acusatorio puro") conscientes de las precisiones necesarias al respecto, tanto en cuanto a la equiparación "acusatorio-adversarial", como al juego del principio de oficialidad derivado de la configuración pública del derecho penal. De hecho, no existe un modelo adversarial puro donde rige el principio de oficialidad en la persecución penal y se atribuye el ejercicio de la acción a un acusador público. Véase al respecto: GOMEZ ORBANEJA, "Comentarios a la Ley de Enjuiciamiento Criminal”, T.II, p. 187; DÍAZ CABIALE, J.A, "Principios de aportación de parte y acusatorio: la imparcialidad del juez", Comares, Granada, 1996, p. 217; y AMODIO. E. "The Accusatorial System Lost and Regained: Reforming Criminal Procedure in Italy", en "Criminal Justice between Crime Control and Due Process" (Convergence and Divergence in Criminal Procedure Systems", Max-Planck-Institut für Auslandisches un internationals Strafrecht, Band, 101, 2004, pp. 23-31.

$6 \quad$ Sobre la denominación “juicio de acusación” se volverá más adelante. 
law" (o continental), así como las necesidades derivadas de una convergencia internacional, han ido poniendo de relieve la existencia de problemas más comunes de lo que hubiera cabido esperar en un principio; a la par que permite percibir dos tendencias parcialmente distintas a la hora de configurar no tanto la investigación -diferente ya de inicio- sino aquella otra fase relativa al juicio de acusación.

Puede constatarse, así, en uno y otro ámbito cuestiones como las siguientes: a) ¿quién debe dirigir la fase investigadora? aspecto generalmente anudado a la naturaleza (jurisdiccional o no) que se predique de la misma; b) ¿quien establece el hecho delictivo y la persona a la que se imputa su comisión? ¿quien puede o debe ejercitar la acción penal; o c) ¿quien enjuicia o controla la correcta conclusión de la etapa investigadora y la necesidad de abrir la fase de juicio?,id est, quien controla el juicio de acusación; y d) ¿forma parte o no del derecho de defensa la participación del imputado en el juicio de acusación?? ${ }^{7}$.

Cada uno de estos interrogantes abre un amplio abanico de respuestas en la realidad de los diferentes ordenamientos jurídicos, cuyo contenido debe examinarse en su contexto históricojurídico y social. Y cada una de ellos, a su vez, resulta condicionado por la estructura concreta de los poderes estatales (singularmente el ejecutivo y el judicial) y las diferentes opciones en torno a la obligatoriedad o no en el ejercicio de la acción penal. Por su parte, la creación de espacios comunitarios como la Unión Europea o la necesidad de instaurar una justicia de ámbito internacional, han obligado a procurar regulaciones armonizadoras, como la del conocido como "Proyecto de Corpus Iuris", limitado no sólo territorialmente a los países comunitarios, sino también en su ámbito objetivo a los delitos económicos; el "Libro Verde" sobre la protección de los intereses financieros y comunitarios y la creación de un Fiscal Europeo propuesto por la Comisión Europea; o la Corte Penal Internacional ${ }^{8}$. Estos instrumentos y especialmente el último por ser el único vigente en la actualidad constituyen elementos de contraste singularmente útiles para resaltar la efectiva existencia de puntos de confluencia, así como para extraer las correspondientes enseñanzas.

\section{El proceso hasta el juicio de acusación en los sistemas del “common law”.}

Los países de los que se predica un sistema "acusatorio puro" eliminan la fase de instrucción, como instancia procesal encomendada a un juez con facultades investigadoras. En realidad, el

Todas estas cuestiones fueron objeto de respuesta específica y plural en un encuentro científico propiciado por el Max Planck Institut de Derecho penal y procesal penal, cuyo contenido y resultados se publicaron en una monografía: Strafjustiz im Spannungsfeld von Effizienz und Fairness (Criminal Justice between Crime Control and Due Process), Convergente and Divergente in Criminal Procedure Systems, Escritos del Max Planck Institut de derecho penal y penal internacional, Número 101, Duncker\&Humblot-Berlin, 2004. 
juez aparece por primera vez a la hora de corroborar la admisibilidad de la acción penal y la legalidad de las actuaciones investigadoras ${ }^{9}$.

En Inglaterra, la policía lleva todo el peso de la investigación lo que permite cernir dudas sobre la efectiva separación entre investigación y acusación ${ }^{10}$. Organizada localmente goza de independencia funcional y disfruta de un amplio margen de libertad de criterio acerca de cuando y como iniciar el proceso penal, reforzado por la "caution" y el "guilty plea"11.

En los EEUU de Norteamérica la investigación se encomienda a la policía con total autonomía. Ésta presenta el resultado al fiscal, quien debe analizar las posibilidades de condena, como aspecto fundamental del juicio de acusación. El control sobre la investigación no corresponde directamente al fiscal; a tales efectos se utiliza la noción de "probable cause" empleada por la IV Enmienda de la Constitución ${ }^{12}$.

Por lo que respecta a la acusación, tanto Inglaterra como los EEUU de Norteamérica han optado claramente por la discrecionalidad en el ejercicio de la acción penal. Sin embargo, mientras Inglaterra ha rechazado siempre un régimen de monopolio del ejercicio de la acción penal y no ha creado un ministerio fiscal propiamente dicho; en los EEUU de Norteamérica la acción penal no pertenece a los ciudadanos, sino que esta legalmente monopolizada por la acusación pública y encomendada a un ministerio fiscal (“Attorney- General” en el ámbito federal o "district attorney" en el local) ${ }^{13}$.

En Inglaterra se acusa en nombre de la Corona; generalmente la policía, y también, si así lo requiere, el Attorney General, el Director of Public Prosecutions o la Crown Prosecution

La configuración "adversarial" del sistema conduce a que la preparación del proceso se encomiende a las partes, teóricamente particulares, si bien de hecho es la policía al incorporar la oficialidad, incluyendo al MF, quien ostenta además una situación de privilegio al corresponderle buscar y analizar la suficiencia de elementos que sostienen la acusación.

10 Como se cuestiona DIEZ-PICAZO, L.M, aunque, cuando un agente de policía se constituye en acusador debe recurrir a los servicios de un abogado para postular, y tal hecho atempera la falta de imparcialidad, no puede negarse que el letrado seguirá las instrucciones de su mandante. Cfr. "El poder de acusar", El poder de acusar", Ariel, Barcelona, 2000, p. 41

11 La caution (amonestación formal sin consencuencias jurídicas) opera como alternativa para el ejercicio de la acción penal, cuya aplicación usa discrecionalmente la policía. El "guilty plea" (admisión de los cargos formulados) permite que la policía no tenga que llevar a juicio un importantísimo porcentaje de casos.

12 La noción de "probable cause" supone la exigencia de "indicios fiables" para poder llevar a cabo una investigación y sobre todo para poder solicitar del juez la autorización para limitar algún derecho básico. Implica algo más que la mera sospecha aunque algo menos de la fundada certidumbre, y se traslada de hecho a la vista preliminar como criterio para verificar la admisibilidad de la acción penal que evite un uso abusivo o intimidatorio de la acción penal.

13 P.L.STRAUSS, An Introduction to Administrative Justice in the United States, Carolina Academic Press, Durham (N.C.), 1989. NIKLAUS SCHMID, "Das amerikanische Strafverfahren. Eine Einfürung), C.F. Müller Juristischer Verlag. Heidelberg, 1986. $1^{a}$ ed., entre otras muchas obras. 
Service $^{14}$. El control para verificar la admisibilidad de la acción penal se realiza a partir de la intervención del propio Crown Prosecution Service, correspondiendo al juez comprobar la existencia de elementos suficientes para proceder, así como que la actividad policial ha sido legal ${ }^{15}$. El juicio de acusación en Inglaterra, originariamente discrecional y atribuido a la policía, encuentra, desde la creación del Crown Prosecution Service, algunas limitaciones, ya que este último puede instar a la policía a adquirir más elementos de prueba o incluso puede desistir del ejercicio de la acción sin el consentimiento de aquella, ocupándose de la dirección técnica de la acusación obligatoriamente ${ }^{16}$. No cabe hablar, empero, de una auténtica garantía jurisdiccional en este aspecto, como por otra parte se explica, tanto por el hecho de la configuración administrativa de la investigación penal, cuanto por el de la ausencia de control jurisdiccional sobre el ejercicio de las facultades discrecionales. Sí existe, no obstante, un control político sobre los criterios que usa la discrecionalidad en el ejercicio de la acción penal ${ }^{17}$. Este juicio de acusación se vierte sobre el fundamento de dicha acción, tanto desde la perspectiva de sus posibilidades de éxito, cuanto de su eventual frustración por las actividades desarrolladas por la policía, si éstas son consideradas ilícitas. Esta encomendado, como se ha dicho, al Attorney General y al Crown Prosecutión Service ${ }^{18}$.

En Estados Unidos la decisión de acusar corresponde al fiscal; este ejercicio, no obstante, esta sometido al control judicial cuando la decisión es positiva. El instrumento procesal es el "complaint" que convierte a la persona en acusado ("denfendant") y debe ser aprobado por el magistrado competente, quien decidirá a la vista de las actuaciones de la policía y del fiscal, sin audiencia alguna del acusado. Si el magistrado valora los hechos como "probable cause" el acusado será conducido a su presencia para la primera comparecencia, cuyo objeto se limita a cerciorarse de la identidad del acusado e informarle de los cargos que se le imputan. Así como la noción de "probable cause" opera como límite mínimo que debe concurrir para iniciar una investigación ${ }^{19}$; la "vista preliminar" (preliminary hearing) constituye un criterio de

14 Aunque el Departamento de Fiscalía de la Corona trabaja estrechamente con la policía, tiene carácter independiente. El Director de Fiscales Públicos es responsable de la elaboración de un "Código para los Fiscales de la Corona" conforme a las disposiciones de la sección 10 de la Ley de Procesamiento de Ofensas de 1985, ofreciendo además asesoramiento sobre los principios generales que debe aplicarse cuando se tomen decisiones sobre los procesamientos. Este "Código para Fiscales de la Corona" informa de las decisiones sobre el procesamiento, tanto al el Departamento de Fiscalía de la Corona, cuanto a la policía. Puede obtenerse en la CPS Website: www.cps.gov.uk

15 Crown Prosecution Service es un servicio público para Inglaterra y Gales encabezado por el Director de Fiscales Públicos. Responde directamente ante el Parlamento a través del Procurador del Estado.

16 A.F.WILCOX, "The Decisión to Prosecute", Butterworths, London, 1972.

17 J.L.J. EDWARDS, “The Attorney-General, Politics and the Public Interest”, Sweet\&Maxwell, London, 1984, L.M. DIEZ-PICAZO GIMENEZ, "El poder de acusar”, Ariel, Barcelona, 2000.

18 El Director of Public Prosecutions, de quien depende directamente el Crown Prosecution Service, es un cargo de libre designación política y está sujeto, eventualmente, a las directrices del Attorney-General (principal asesor jurídico del Gobierno, aunque no forma parte del Gabinete).

19 Sobre la noción de probable cause vid. J.H.ISRAEL y W.R. LA FAVE, "Criminal Procedure (Constitucional Limitations), 4ª ed, West Publishing Co., St Paul (Minn.) 1998. 
admisibilidad, fundado, generalmente, en comprobar que hay elementos suficientes para proceder, así como que las pruebas de cargo han sido legalmente obtenidas. En el derecho federal a la vista preliminar sigue el procedimiento de "indictement" si se trata de delitos menos graves ("misdemeanor") o de "information" si son graves ("felony"). En el primero la decisión corresponde al juez; en el segundo a un gran jurado. En el derecho de los diferentes Estados, el derecho a ser incriminado por un jurado (V Enmienda) no ha sido declarado aplicable, lo que justifica que se limite su operatividad ${ }^{20}$.

\section{El proceso hasta el juicio de acusación en los sistemas continentales.}

Caracteriza a los sistemas continentales una configuración formal de la acción penal en la que los deberes y poderes asignados al órgano oficial de la acusación (el Fiscal) abarcan una llamativa variedad en los diversos ordenamientos, en una línea, uno de cuyos extremos sería la obligatoriedad en el ejercicio de la acción penal (Italia; España) y el otro, los ordenamientos del "common law", pasando por un sistema intermedio en el que la obligatoriedad admite modulaciones (Alemania, Francia).

Este último aspecto no es ajeno a concepciones jurídico-políticas diversas que no conviene olvidar a la hora de efectuar una valoración global. Los ordenamientos que proclaman el principio de obligatoriedad en el ejercicio de la acción penal dan prioridad a valores como el carácter no dispensable ni instrumental de la legalidad, la seguridad jurídica y la igualdad ante la ley. En cambio, los ordenamientos que acogen la discrecionalidad en el citado ejercicio otorgan mayor importancia a la representatividad en la aplicación de la ley, la legitimad democrática y la responsabilidad política ${ }^{21}$.

Así, a título de ejemplo, en Francia, el Código Procesal Penal de 1808 instituyó el sistema "acusatorio formal": un órgano, el Ministerio Público, dependiente del ejecutivo se encarga del ejercicio de la acusación, pero corresponde a la autoridad judicial la responsabilidad de investigar los hechos delictivos e iniciar el proceso. El uso correcto del ejercicio de la acusación no está exento de control, tradicionalmente a cargo de la "Chambre d'accusation", instrumento relativamente similar al Jurado de acusación inglés ${ }^{22}$.

Cabe una tercera revisión, a través de la revisión del Gran Jurado, formado por 16 a 23 ciudadanos, quienes vuelven a examinar las actuaciones y medios de pruebas aportados, así como el "indictment" del fiscal. Si se aprueba el proceso continúa; en caso contrario, procede la absolución definitiva. Solo a partir de ahí, se informa al acusado del "arraignment" (cargos que se le imputan) manifestandose sobre su culpabilidad o inocencia o "nolo contendere" en los casos de "plea bargaining".

$21 \quad$ DIEZ-PICAZO GIMENEZ, L.M, "El poder de acusar" cit. p.31-32.

22 Cfr. ARMENTA DEU, T, "El fiscal instructor ¿es necesario? En "Cuadernos de Derecho Público”, n. 16. mayoagosto, 2002, p205ss. 
La "Chambre d'accusation es esencialmente una jurisdicción de instrucción de segundo grado para los delitos graves (crimes); de hecho es una sección de la Corte de apelación. Le corresponde controlar las actividades de la policía judicial (art. 224 CPP), así como revisar lo actuado por el juez de instrucción con amplias facultades (art. 201ss CPP); promover la acusación del inculpado y enviarlo a la Cour d'assises (art. 214 y 214 CPP) ${ }^{23}$. Tras sucesivas reformas del Código Procesal penal, examina si existen contra el inculpado cargos suficientes a través de un procedimiento donde existe contradicción y la posibilidad de que el imputado ejerza su derecho de defensa presentando alegaciones (art. $211 \mathrm{CPP}$ ).

La reforma procesal de enero de 1993, inspirada en el "informe Delmas Marty" que postulaba encomendar a la Fiscalía las funciones de investigación y a otro juez las decisiones sobre derechos fundamentales, fue modificada por otra de 24 de agosto de 1993, devolviendo al juez de instrucción las facultades para decidir sobre la prisión preventiva ${ }^{24}$. Tal reversión obedeció a que la sospecha de prejuicios recaída sobre la figura del juez por ser quien investiga y debe decidir sobre la existencia de acción penal (hechos presuntamente delictivos e imputado) se trasladaba al fiscal, quien concentró en su persona la investigación sobre la concurrencia de tales hechos y sujetos y la decisión sobre el ejercicio de la acción. Esta es una de las principales conclusiones de la llamada "Comisión Truché" 25 .

Posteriormente la Loi $N^{o} 2000-516$ du 15 juin 2000 renforçant la protection de la présomption d'innocence et les droits des victimes ha consagrado la atribución de la competencia de la detención provisional a un juez diferente del instructor (le juge des libertés et de la détention) de manera semejante a la reforma española que exigió la petición de un acusador para poder adoptar la medida de prisión provisional, sin que se haya vuelto a cuestionar (s.e.u.o) la instrucción judicial ${ }^{26}$.

b) En Italia la reforma del CPP de 1989 se decantó por una clara aproximación al sistema acusatorio "puro" sustentado en dos pilares: la estricta separación entre las funciones del fiscal y del tribunal, propiciando un auténtico "proceso de partes", y la clara diferenciación entre fase previa al juicio y fase judicial. Desde esas fechas, se han observado diversas reacciones frente al sistema incorporado: inicialmente de claro repudio, y tras él de acomodación a los principios originales que inspiraron la reforma y el derecho de defensa y la igualdad de las partes,

\footnotetext{
23 Conoce también de las apelaciones contra resoluciones del juez de instrucción (arts. 185 a 187 y 207 CPP). GASTON STEFANI; GEORGES LEVASSEUR y BERNARD BOULUC, "Procédure pénale", Dalloz, 13 ed. 1987.

24 Vid. "El caso francés" en la obra colectiva "Crisis del sistema político, criminalización de la vida pública e independencia judicial", en "Cuadernos de Derecho judicial", Madrid, 1998, p. 137ss.

25 Este "Informe de la Comisión de Reflexión sobre la Justicia”, elaborado en Francia en 1977, recibe el nombre del presidente de la corte de Casación al que se encomendó su presidencia.

26 ANNE CRENIER, en AAVV “Sistemas de proceso penal en Europa”, Cedex, Barcelona, 1998, p. 169-170.
} 
notablemente mermadas en virtud de aquella ${ }^{27}$.

A partir del rechazo de la discrecionalidad en el ejercicio de la acción penal, sosteniendo la sujeción al principio de oficialidad, y la vigencia del principio de legalidad -que no impide diversas manifestaciones de aplicación del "principio del consenso"- la deriva hacia la instauración del acusatorio no ha resultado sencilla, ni puede afirmarse a día de hoy que completa. Por citar simplemente algunas "contradicciones" detectadas por la doctrina y tribunales italianos: la estricta separación entre fase previa y de juicio, encomendándose la primera al fiscal, originó que muchas diligencias carecieran de eficacia probatoria posteriormente en el juicio, en tanto el juez de tal fase tendió a concebir su función como mero notario; a la par que una y otra circunstancia, al apartarse de la idea anglosajona de constituir un mecanismo en virtud del cual el acusado tiene conocimiento del estado de las investigaciones (discovery device), derivara en la crisis de éste último ${ }^{28}$. A ello se unieron diversos casos de impunidad por la falta de iniciativa del fiscal, que condujeron a que la Suprema Corte decidiera incrementar las facultades judiciales en determinados supuestos ${ }^{29}$. De esta forma, reformas posteriores, especialmente la de 1999, modificaron la configuración de la fase previa al juicio, ampliando las facultades del juez, quien puede usar evidencias para archivar el juicio u ordenar al fiscal que amplíe la investigación si la considera insuficiente ${ }^{30}$. El juicio de acusación se realiza sin publicidad y con la necesaria presencia del imputado y su defensor, y el fiscal. La udienza preliminare se articula como instrumento para un control negativo sobre el ejercicio de la acusación, como filtro para hacer decaer acusaciones infundadas, y en el que, además, se da entrada al imputado para su defensa haciendo posible el contradictorio, para que el juez resuelva sobre la apertura del dibattimento (juicio oral) (arts. 416 a $433 \mathrm{CPP})^{31}$.

De otro lado, y en orden a equilibrar las diferentes fuerzas del fiscal y el imputado como partes opuestas, salvaguardando los derechos del acusado, se ha reintroducido la figura del juez como garante; propiciando el conocimiento de las actuaciones por parte del imputado; y

Acta del Parlamento Italiano, no 335/1995. AMODIO, "Reforming Criminal Procedure in Italy", ob.cit. p.27. El "discovery" opera como mecanismo que procura compensar la innegable desigualdad del modelo adversarial, que sitúa a la defensa respecto del MF en clara inferioridad práctica y probatoria. En tal sentido, FRIGO, G, "Nuovi poteri d`iniciativa e nuove responsabilità del difensore" en "Il nuevo codice di procedura penale visto dall'estero", Milano 1991. En su virtud, se obliga a las partes a descubrir las fuentes de prueba con que se cuenta antes de la vista o al iniciarse ésta. Un comentario al respecto en DÍAZ CABIALE, J,A, "Principios de aportación de parte y acusatorio..", cit. p. 259ss y notas 156 y 172.

29 Sentencia $\mathrm{N}^{\circ}$ 111/1993, citada por Amodio, ob.cit.loc.cit.

30 Arts. 421 bis; 422 y 425 CPP. El juez ante el que se desarrolla la "udienza preliminare" puede indicar a las partes "temas nuevos o incompletos sobre los cuales estima necesario adquirir informaciones ulteriores para decidir" (art. 422.1 CPP).

31 El art. 421 CPP regula una discusión oral y con inmediación entre acusación y defensa, quienes exponen al juez sus conclusiones con arreglo al material obtenido en la instrucción y depositado en Secretaria (art. 416.2 CPP) ante un juez imparcial. AMODIO, E, "L'Udienza preliminare nel nuevo processo penale" en Casazione penale, n.2, 1988, p. 2172. 
garantizando determinadas investigaciones de la defensa. Así: el juez puede archivar el caso cuando las actuaciones por ilegales o inadecuadas no conduzcan a una "probable cause"; el fiscal debe dejar constancia de sus actuaciones para que el acusado pueda conocerlas una vez la investigación se da por concluida; y la Ley 397/2000 dedica nueve artículos a regular derechos de la defensa a la hora de desarrollar sus propias investigaciones ${ }^{32}$.

La última etapa ha sido la inclusión en la propia Constitución italiana del art. 111 que incorpora los derechos contemplados en el art. 6 de la CEDH, específicamente, la igualdad entre las partes; la imparcialidad y neutralidad del juez y el derecho a un proceso sin dilaciones indebidas; de manera que la configuración del derecho de defensa en Italia deberá completarse con el espíritu y letra del citado art. $6 \mathrm{CEDH}$. Debe resaltarse, que esta reforma reconoce la necesidad de tal interpretación ante la insuficiencia del sistema acusatorio incorporado en la reforma de 1988, desde el punto de vista de las garantías procesales del imputado ${ }^{33}$.

\section{Dos modelos de ámbito internacional en sendos proyectos europeos y el de la Corte Penal Internacional.}

Buen ejemplo de las tendencias señaladas en los dos apartados anteriores lo ofrecen, por una parte, las dos iniciativas legislativas de la Unión Europea (el conocido como "Corpus Iuris" y el Libro Verde sobre la protección de los intereses financieros y comunitarios y la creación de un Fiscal Europeo) ${ }^{34}$; y por otra, la Corte Penal Internacional ${ }^{35}$. En los dos primeros textos se aprecia el interés en preservar la imparcialidad del fiscal (el europeo en este caso) en sus funciones acusadoras; en tanto la estructura de la Corte Penal Internacional opta por una configuración más cercana a la de los paises del "common law", con un claro objetivo de control del ejercicio de la acusación.

\section{1 "Corpus Iuris de disposiciones penales para la protección de los intereses financieros de la Unión Europea" ${ }^{36}$}

En el sistema propuesto por la Comisión de expertos encargada de elaborar un texto normativo de tal índole, junto a un MF (PP) a cuyo cargo está el inicio de las investigaciones y

\footnotetext{
Art. 391bis CPP.

Legge Constituzionale, de 23 de noviembre de 1999, publicada en la Gaceta Ufficiale, del 23 de diciembre de 1999.

34 COM (2001) 715 final. http://www.europa.cu.int/comm/anti fraud/index es.html. Sobre el mismo existe también un Documento de trabajo del Parlamento Europeo sobre el Libro Verde, PE 315.771, de 26 de junio de 2002.

35 Estatuto del Tribunal Penal Internacional, aprobado en Roma el 17 de julio de 1998 (en adelante CI). Instrumento de Ratificación publicado en el BOE de 27 de mayo de 2002, y vigente en España a partir del 1 de julio de 2002.
}

36 En adelante $\mathrm{CI}$. 
Juicio de acusación, imparcialidad del acusador

y derecho de defensa

su dirección, se prevé la intervención de un denominado "juez de las libertades" en la fase instructora y a la hora de formular el "juicio de acusación" ${ }^{37}$. El periodo de enjuiciamiento queda en manos de cada Estado miembro, quien designará el juez de entre los nacionales, aplicando las normas de competencia de derecho interno ${ }^{38}$.

El fiscal europeo es el responsable de la instrucción ${ }^{39}$. Esta se inicia "ex officio" o a instancias de cualquier ciudadano, siempre y cuando, trasladada la denuncia, el fiscal aprecie que constituyen alguna de las cuestiones planteadas en los arts. 1 a 8 del "Corpus Iuris". El FE debe ser informado de los hechos que puedan constituir las infracciones anteriormente señaladas por las autoridades nacionales (policía, fiscales, jueces de instrucción, agente de las administraciones nacionales, etc, art. 19.1 CI); el órgano comunitario competente (la UCLAF); cualquier ciudadano o la propia Comisión ${ }^{40}$.

Cuando el FE resuelve no acusar, la decisión es irrecurrible, salvo en el supuesto de que acepte remitir la solución a una transacción. Se trata, pues, de un ejercicio discrecional sin posible control posterior judicial, con la excepción señalada ${ }^{41}$. Por el contrario, sí se prevé la posibilidad de recurrir la resolución que decide acusar (art. 21.3.if CI), debiendo ser notificada en las mismas condiciones que la de no acusar (art. 21.2 CI) mencionando el nombre y dirección del acusado, la descripción de los hechos y su calificación, así como la jurisdicción nacional a la que se remite.

La participación del juez de garantías en la fase preparatoria del proceso (art. $25 \mathrm{CI}$ ) se orienta fundamentalmente a cumplimentar la "garantía jurisdiccional", consecuencia obligada de atribuir la instrucción al fiscal europeo, a la hora de adoptar cualquier medida limitativa de los derechos y libertades reconocidos en el Convenio Europeo de los Derechos del Hombre,

37 Se trata de un juez nacional con arreglo a las normas orgánicas del país de que se trate (art. 25 bis CI).

38 Sin perjuicio de la reserva de competencia a favor del Tribunal de Luxemburgo, competente para resolver los conflictos de competencia (art. 26.1 CI).

39 Este fiscal es independiente, tanto de las autoridades nacionales como de los órganos comunitarios y está compuesto por un Fiscal General Europeo, con sede en Bruselas y Fiscales Europeos Delegados en cada capital de cada Estado miembro. Su actividad esta sometida al principio de legalidad con tres excepciones (art. 19,4 CI). El ejercicio de la acción se atribuye al FE casi en régimen de exclusiva. Junto a éste pueden actuar los fiscales nacionales, aunque únicamente si así lo exigen los intereses nacionales en cuestión (art. 22.1 CI). No se prevé la posibilidad de que se constituyan como parte, ni el ofendido por el delito, ni el acusador popular.

40 Las autoridades tienen la obligación de solicitar la intervención del FE a más tardar cuando se ejercita la acusación o en el momento de dictar medidas cautelares. Si las investigaciones realizadas por las autoridades nacionales revela la existencia de alguna de las repetidas infracciones, el expediente debe ser remitido inmediatamente al MFE.

41 La decisión puede consistir en: a) trasladar las actuaciones a las autoridades nacionales para que continúen el procedimiento; b) archivar las actuaciones, cuando el acusado reconozca su culpabilidad, repare el daño causado y restituya los fondos; o, c) autorizar que la autoridad nacional que instó la persecución, transija, siempre y cuando lo haga con arreglo a lo establecido en el art. 22.2.b CI. CHIAVARIO, M. Linee del sistema processuale penale comunitario en PICOTTI (editor), "Posibilita e limiti di un Diritto Penale dell'Unione europea" p. 200. 
así como a examinar la regularidad del procedimiento preparatorio desarrollado, antes de reenviarlo a la jurisdicción nacional correspondiente ${ }^{42}$. A este juez se le encomienda un claro control sobre el "juicio de acusación" si la decisión del FE resuelve enviar el caso a juicio, como hemos visto (art. 25,3 CI). La atribución de esta facultad a dicho órgano ha sido criticada poniendo en duda su imparcialidad, y defendiendo en consecuencia la conveniencia de ser sustituido por un órgano comunitario, concretamente, una Sala del Tribunal Europeo de Justicia. Resulta IIustrativo, en efecto, que una de las primeras voces de alarma, aún en fase embrionaria, provenga precisamente de uno de los miembros de la Comisión redactora del CI ("Cristine van den Wyngaert" $)^{43}$.

El juez de las libertades convocará a una audiencia al MFE y al acusado para confirmar los cargos que fundamentan la decisión de enviar el caso para su enjuiciamiento. Se valorará si está en condiciones de ser juzgado, así como, si a tenor de las pruebas -mejor diligenciasrealizadas durante la investigación aparecen razones suficientes para creer que el acusado cometió el delito que se le imputa ${ }^{44}$.

Finalmente, el "juez de las libertades” revisará, además, la regularidad del procedimiento. No queda claro el ámbito de ésta última facultad. El art. 25.3 CI señala de manera expresa: $A l$ final de la fase preparatoria, si el FGE decidiera enviar el caso a juicio (cf.art. 21.1 y 3 CI) someterá su decisión al juez de las libertades, quien verificará la regularidad de todo el procedimiento y excluirá -en su caso- las pruebas que hubiesen sido ilegalmente obtenidas de acuerdo a las reglas expuestas a continuación (art. 32 CI) dando la intervención correspondiente a la jurisdicción de reenvío según las reglas determinadas en el art. 26. A tenor de dicho precepto ¿Puede el juez de las libertades entrar en consideraciones sobre la fundamentación de la acción penal, más allá de garantizar la legalidad en los método utilizados para su investigación? Dicho en otro términos, preservada la regularidad procedimental ¿cabría que el juez de las libertades se pronunciase sobre la adecuación del ejercicio de la acción penal? Y de ser así, ¿se compadece tal configuración con un modelo adversarial o uno acusatorio?

\subsection{Libro Verde sobre la protección de los intereses financieros y comunitarios y la creación de un Fiscal Europeo}

\footnotetext{
42 Entre sus atribuciones más relevantes se encuentra la de cursar la "orden de detención europea" a instancias del fiscal europeo (art. $25 \mathrm{CI}$ ).

43 Cfr. Corpus Iuris, Ministerio Fiscal Europeo y juicios nacionales para eurocrímenes: ¿es necesaria una Sala de Justicia Europea para la fase previa? Corpus iuris, european public prosecution and national trials for eurocrimes: is there a need for a European pre-trial chamber?, Agonn. № 24, October 1999.

44 La resolución del juez de las libertades puede, a su vez, ser objeto de recurso por parte del FE y del acusado. Dicho recurso debe ser regulado por cada estado miembro, con arreglo a lo dispuesto en el art. $35 \mathrm{CI}$ (Complementariedad del derecho nacional). La mise en oeuvre du Corpus Iuris dans les États embrees, M. DELMAS-MARTY y J.A.E. VERVAELE (ed), Vol.I, Intersentia,, 2000, Annexe III.
} 
Por su parte, la propuesta de la Comisión de las Comunidades Europeas, denominada Libro Verde sigue un modelo muy semejante, empezando por la posible creación de un Fiscal Europeo. Sin entrar ahora en el amplio abanico de cuestiones que tan sugerente tema plantea, sí quiero destacar una única cuestión en relación con el tema que nos ocupa. La investigación y la acusación se encomiendan al fiscal europeo, en tanto el "juez de garantías" subviene a la necesidad de "garantía jurisdiccional" en determinadas actuaciones, como todas aquellas limitativas de derechos fundamentales. Unido a ello, el apartado 6.4 del citado Libro Verde, le encomienda la revisión del ejercicio de la acción penal controlando la apertura del juicio, confirmando los cargos en virtud de los cuales el Fiscal Europeo se propone actuar, así como la validez del sometimiento al tribunal en cuestión. En sus propios términos: Se trata de examinar si las pruebas son suficientes y admisibles y si el procedimiento seguido es regular, con el fin de evitar un proceso ilegítimo y la consiguiente estigmatización del acusado. A partir de este texto, la propia Comisión Europea abre un haz de interrogantes suficientemente expresivos como para no necesitar mayor comentario y cuyo doble eje son las dos siguientes: ¿a quién debe confiarse la función de control de los actos de investigación realizados bajo la autoridad del Fiscal Europeo? (Pregunta $\mathrm{n}^{\circ}$ 12) y ¿A quién debe confiarse la función de control de la decisión sobre la apertura del juicio? (Pregunta $n^{\circ} 13$ ).

\subsection{Tribunal Penal Internacional.}

La última variante a la que quiero hacer referencia es el Tribunal Penal Internacional ${ }^{45}$. Regulado en el Estatuto de Roma, encomienda la investigación y el ejercicio de la acusación al Fiscal (art. 15ss ECPI). Ahora bien, ambas competencias se ejercen de manera tutelada ya que, tanto la decisión de ejercitar la acción penal, cuanto la adopción de determinadas medidas en la instrucción, se encuentran sometidas a la autorización de un órgano de la Corte, la Sala de Cuestiones Preliminares (art. 15.3 ECPI). De hecho, el modelo resultante, como fruto de un consenso largo y arduo se encuentra a caballo de los dos a los que venimos referencia, decantándose en la fase investigadora y de ejercicio de la acusación, más hacia el sistema continental, aunque la instrucción se atribuya al fiscal ${ }^{46}$.

España publicó la LO 18/2003, de 10 de diciembre, de Cooperación con la Corte Penal Internacional. Regulando los aspectos orgánicos procesales y procedimentales que permiten aplicar el Estatuto, cuyo contenido no afecta directamente al objeto de este estudio.

46 Argumenta que apoya, entre otros, que tal característica ni es necesaria ni suficiente para caracterizar un sistema como acusatorio, aunque probablemente sí uno adversarial. El acusatorio se salvaguarda si quien acusa no juzga, como también si quien investiga no juzga, separando juez instructor e investigador; no así un modelo adversarial entendido éste como contienda entre partes, para lo que resultaría imprescindible que el fiscal investigara, como el defensor, y el juez actuara como tercero imparcial y garante. Sobre el par fiscal instructor-principio acusatorio, véase, ARMENTA DEU, T. "El fiscal instructor ¿es necesario? En "Cuadernos de Derecho Público", n.16. mayo-agosto, 2002 y también la obra de Gomez Colomer citada en esta nota en sus pp. 108ss, Sobre la configuración adversarial: DÍAZ CABIALE, J.A, "Principios de aportación de parte y acusatorio..”, cit. p. 213ss. En torno al carácter mixto del procedimiento adoptado, GÓMEZ COLOMER, J.L, 
El Fiscal puede iniciar una investigación, si previo análisis de la documentación aportada, unida a la que pueda recabar él mismo con arreglo al art. 15.2 ECPI, obtiene la preceptiva autorización de la Sala de Cuestiones Preliminares. Esta última examinará si existe fundamento suficiente para investigar y si los hechos son alguno de los contemplados en los arts. 1 a 8 del Estatuto (art. 15.4 ECPI) ${ }^{47}$. La aprobación debe ser mayoritaria (al menos dos de tres). Si la Sala de Cuestiones Preliminares no autoriza la investigación, el Fiscal podrá presentar ulteriores solicitudes basadas en nuevos hechos o pruebas (art. 15.5 ECPI).

Tras las indagaciones que estime pertinentes, y en las que resultarán decisivas la cooperación internacional y la asistencia judicial Parte IX (arts. 86ss del ECPI), el fiscal resuelve, denegando la apertura o admitiéndola ${ }^{48}$. Si decide abrir la investigación, el Fiscal remitirá a la Sala de Cuestiones Preliminares una petición de autorización a tal efecto (art. 15,3 ECPI), quien resolverá mediante una resolución irrecurrible (art. 15.5 ECPI $)^{49}$.

No se contempla la intervención del sujeto investigado en la investigación, ni por ende, la posibilidad de solicitar diligencia alguna de su interés. Este hecho redunda en una limitación

"El Tribunal Penal Internacional: Investigación y acusación”, Tirant lo Blanc, Monografías, Valencia 2003, p. 80; MONTON REDONDO, A, "Apuntes sobre la Corte Penal Internacional en el marco de de la justicia universal" en "Libro homenaje al Prof. Dr. Eduardo Font Serra", Madrid, 2004.

47 El inicio de esta fase se atribuye al fiscal, ya sea de oficio, ya a instancias de un Estado miembro o del Consejo de Seguridad de la ONU. La ONG no tienen reconocida una iniciativa a tal efecto; sin embargo, puede ser objeto de consultas por el Fiscal, para comprobar la veracidad de la denuncia (art. 15.2 ECPI). La investigación se sujeta al citado "principio de subsidiariedad". El fiscal debe dar traslado al Estado en que se hubiera desarrollado la investigación, para que asuma su competencia, solicitando la inhibición de la Corte. Esta inhibición esta sujeta a recurso, del Estado o del propio fiscal (arts. 18.4; 19.6 y 81.1.a ECPI.) En el desarrollo de la investigación -sobre el que no es posible detenerse más ahora- se regula, art. 54, la actividad del Fiscal, y en el 55, lo relativo a los derechos de los sujetos sometidos a dicha actividad.

Como es conocido, el TPI sólo puede ejercer su competencia tras la remisión al Fiscal de una situación fáctica que conlleve la posible comisión de uno o varios crímenes definidos por el Estatuto. La remisión puede hacerse por: a) un Estado parte (art. 13 (b),14; b) el Consejo de Seguridad de la ONU (art. 13 (b); o c) un Estado no parte (art. 12 (3).

$48 \quad$ La negativa puede obedecer a que 1) no haya elementos suficientes para creer que se ha cometido un crimen competencia de la Corte; o que la causa será inadmitida; o, 2) aun existiendo motivos suficientes para abrir la investigación existen razones para creer que, aun teniendo en cuenta la gravedad del crimen y los intereses de las víctimas, una investigación no redundaría en interés de la justicia. Siendo así, debe comunicar tal decisión al Estado que presentó la solicitud y a la Sala de Cuestiones Preliminares y que revisará su decisión. De hecho, compete a la Sala de Cuestiones Preliminares completar la actividad investigadora del fiscal, si la estima insuficiente (art. 56.3. a) ECPI). Esta actuación puede ser recurrida por el propio fiscal (art. 56.3.b) ECPI).

49 La Sala de Cuestiones Preliminares tiene atribuidas, por otra parte, un amplio abanico de funciones en la fase instructora que conducen a fundamentar el "juicio de acusación”: a) Aprobar la solicitud del Fiscal de emitir una orden de detención (art. 58); y una vez se entregue al individuo confirme los cargos (art. 60.2 ECPI) ${ }^{50}$; b) Adoptar las medidas necesarias para preconstituir la prueba en casos en que se presente una oportunidad única de proceder a una investigación (art. 56); c) Dictar determinadas órdenes y providencias necesarias para la investigación (art. 57); y, d) Emitir, a solicitud del fiscal orden de detención o comparecencia (art. 58 ECPI). 
indudable del derecho de defensa, auspiciado además por la distinción entre los derechos del imputado (art. $55 \mathrm{ECPI}$ y los del acusado (art. $67 \mathrm{ECPI}$ ). Resalta en tal sentido la "configuración de mínimos" del derecho de defensa: el imputado tiene derecho a ser asistido por un Abogado defensor de su elección, y si no lo tuviere, a que se le asigne un defensor de oficio "cuando fuere necesario en interés de la justicia" (art. 55.1.c ECPI), y cabe, además, que renuncie a la presencia del letrado en el interrogatorio (art. 55.1.d) ECPI). Se contempla incluso la posibilidad de celebrar la audiencia ante la Sala de Cuestiones preliminares en ausencia del acusado (art. 61.2 ECPI); y se permite la autodefensa ${ }^{50}$. Más allá de estas limitaciones se reconocen toda una serie de derechos una vez se ha formulado la acusación ${ }^{51}$.

Tiene lugar seguidamente la "Audiencia para confirmar cargos" y "controlar la acusación". Una vez el imputado haya sido entregado a la Corte o haya comparecido voluntariamente o en virtud de una orden en tal sentido, la audiencia sirve para informarle de sus derechos, decidir sobre su situación personal (art. 60 ECPI), y confirmar los cargos, es decir, resolver sobre el juicio de acusación (art. $61 \mathrm{ECPI}$ ) de forma idéntica al pre tryal" del proceso americano ${ }^{52}$.

La audiencia termina con una de las tres posibles decisiones: 1) confirmar los cargos y asignar al acusado a una Sala de $1^{\mathrm{a}}$ Inst; 2 ) no confirmar los cargos respecto de los que determine que las pruebas no son suficientes; y 3) levantar la audiencia e indicar al fiscal que presente nuevas pruebas; lleve a cabo nuevas investigaciones o modifique un cargo en razón de que las pruebas presentadas parecen indicar la comisión de un crimen distinto del que es competencia de la Corte (art. 61.7.c) ii ECPI).

\section{Juicio de acusación en los procesos penales españoles recientemente reformados: la posición del imputado.}

De entre los temas suscitados en las reflexiones anteriores centraré mi atención en la posición del imputado en el juicio de acusación, excluyendo toda mención a la exigencia de imparcialidad tanto en la fase investigadora como en el juicio de acusación, en la medida en son ya muchos los trabajos publicados al respecto y mi posición quedó de relieve en otro a cuyo contenido me remito, excediendo ahora los límites de este artículo volver sobre aquél ${ }^{53}$.

Art. 67.1, d ECPI. Aspecto discutible teniendo en cuenta los delitos de los que conocerá este Tribunal. Artículo 67 ECPI.

La repetida Sala debe asegurarse de que el acusado conoce los crímenes que se le imputan, decidir sobre la libertad del detenido y celebrar una audiencia en la que el fiscal se pronunciará sobre si confirma los cargos e informará de las pruebas en que fundamenta su decisión y a la que acudirá el acusado con su defensor. Será la Sala quien confirmará los cargos o no, y en su caso, instará al fiscal para recabar nuevas pruebas (art. 61 ECPI). Mi posición en: ARMENTA DEU, T. "El fiscal instructor ¿es necesario? En "Cuadernos de Derecho Público", n.16. mayo-agosto, 2002. En contra de lo que se afirma, no resulta una posición minoritaria: véase: GÓMEZ COLOMER, J.L, "La Instrucción del proceso penal por el Ministerio Fiscal: Aspectos estructurales a la luz del 
Me centraré, por tanto, en el segundo frente abierto, la posición del imputado en el juicio de acusación, cuestión que ofrece el interés añadido de haber sido objeto de una propuesta prelegislativa concreta en la última reforma de la Ley de Enjuiciamiento Criminal, aunque no fuera incluida en el texto legislativo finalmente aprobado.

La exclusión del imputado de la fase intermedia fue criticada desde los primeros comentarios a la reforma de la Ley de Enjuiciamiento Criminal de 1988 y constituyó causa directa de las cuestiones de inconstitucionalidad resueltas por la STC 86/1990. Esta situación había sido objeto de previas resoluciones del mismo Tribunal Constitucional que afirmaban que el inculpado debe tener oportunidad de participar para poder alegar lo que estime oportuno respecto a la suficiencia de las diligencias sumariales, la procedencia de apertura del juicio oral o el sobreseimiento (STC 44/1985 y 66/1989) ${ }^{54}$.

La cuestión de inconstitucionalidad se planteó en torno al art. 790.1 LECrim en la redacción de la LO de 15 de junio de 1988, de reforma de la Ley de Enjuiciamiento Criminal, suscitando nuevamente la citada exclusión, así como el diferente trato otorgado a las partes acusadoras en relación con la vinculación del juez a la petición de diligencias complementarias. En contra de la doctrina sentada en las sentencias citadas anteriormente, la STC 186/1990 declaró constitucional el esquema legal consagrado en los art. 789 y 790 ALECrim y singularmente este último precepto (STC 186/1990) ${ }^{55}$.

derecho comparado" en R.P.J. N.64, 4 trim. 2001; DE LA OLIVA; "Jueces imparciales, fiscales investigadores y nueva reforma para la vieja crisis de la justicia penal", Madrid, 1988 y "El futuro del proceso penal y el papel del Ministerio Fiscal" en Tribunales de Justicia, n.1, Enero 1997, pp.9 y ss; DIEZ-PICAZO GIMENEZ, L.M, "El poder de acusar", Ariel, Madrid, 2001; ORTELLS RAMOS, M, "Nuevos poderes para el Ministerio Fiscal: aspectos estructurales a la luz del derecho comparado", Revista del Ministerio Fiscal, n.4, 1997; p.104; SANCHIS CRESPO, C. "El Ministerio Fiscal y su actuación en el proceso penal abreviado. Especial referencia al procedimiento preliminar fiscal", Ed. Comares, Granada, 1995; DEL MORAL GARCIA, A, "Ministerio Fiscal y reforma de la justicia" en "Jueces para la democracia, n.43, marzo 2002, p.19 a 27; TORRES-DULCE, E, "La posición del fiscal en la investigación penal: la reforma de la Ley de Enjuiciamiento Criminal", Colección Centro de Estudios Jurídicos, Aranzadi, Pamplona, 2005. Puede encontrarse una amplia relación de autores que se pronuncian, con mayor o menor intensidad, en contra de la atribución de la instrucción al Ministerio Fiscal, en MARTÍN PASTOR, J; "El Ministerio Fiscal como director de la investigación oficial en el proceso penal", Real Colegio de España, Bolonia, 2005, p. 108, nota al pie 193. Debe añadirse, por otra parte, que la gran mayoría de estos análisis sólo contemplan la imparcialidad relativa a que no instruya y juzgue el mismo órgano. Existen pocas referencias al otro plano de imparcialidad en el juicio de acusación (quien investiga no acusa). Claro que éstas deberían suscitarse entre aquellos partidarios de encomendar la instrucción al fiscal.

54 En una interpretación correctora del art. 627 LECrim sentó la doctrina conforme a la cual el inculpado debe tener oportunidad de participar en la fase intermedia (en el proceso ordinario, por tratarse de un recurso en torno a este proceso, pero extensible al resto de los procesos penales (ex art. 622.1 ALECrim y el tenor literal de la propia resolución).

55 La cuestionada inconstitucionalidad del 790.1 ALECrim se centraba en varios aspectos: 1) la exclusión del imputado de la fase intermedia antes de que el juez de instrucción resuelva lo pertinente acerca de la apertura o no del juicio oral; y 2) la imposibilidad de que el imputado solicite el archivo o sobreseimiento de las actuaciones o la práctica de diligencias instructoras, estando así abocado a soportar un juicio oral en cuya 
Juicio de acusación, imparcialidad del acusador

y derecho de defensa

Esta resolución objeto de múltiples comentarios obligaba al imputado a concentrar en la comparecencia del art. 789.4 ALECrim todas sus alegaciones en orden a que el juez dictara alguna de las resoluciones del art. 789.5, $1^{\mathrm{a}}, 2^{\mathrm{a}}$ y $3^{\mathrm{a}} \mathrm{ALECrim}^{56}$; así como aquellas relativas al sobreseimiento que quedaban de esta manera fuera de su alcance hasta el momento de redactar el escrito de defensa ${ }^{57}$.

A partir de esta sentencia, o quizás para encontrar explicación a una valoración tan diferente de los derechos de defensa del imputado en la fase intermedia, en el proceso ordinario y en el abreviado, se ha querido ver dos finalidades diferentes del periodo intermedio, consagrando para el segundo la utilización del término "juicio de acusación"58.

Ocurre, sin embargo, que tampoco convence la tesis que defiende tal diversidad, salvo, claro está, que ésta sólo atienda a la posición procesal del imputado sin mayor justificación ${ }^{59}$. Esta desigualdad se traslada, además, a las partes acusadoras y la solicitud de diligencias complementarias, persiguiendo justificar así una posición preeminente del órgano oficial de la acusación claramente discutible desde la perspectiva de un sistema acusatorio, y absolutamente rechazable tratándose de otro adversarial ${ }^{60}$.

preparación no ha tenido intervención. Se planteaba que tal regulación ocasionara indefensión, ya que la primera oportunidad que tenía para rebatir la acusación sería la presentación del escrito de defensa, impidiéndole así persuadir al tribunal sobre la improcedencia de abrir el juicio oral. El Tribunal Constitucional entendió salvaguardado el derecho de defensa en atención a dos preceptos que permitían "una interpretación constitucionalmente adecuada" de manera que la vulneración del derecho de defensa desaparecía a su juicio atendiendo a un doble motivo: a) la obligada comparecencia o interrogatorio judicial del art. 789.4 ALECrim, donde se informa de la imputación e ilustra de los derechos; y b) la posibilidad de recurrir contra el auto que ordena continuar el juicio oral (art. 789.5.4 ALECrim (abriendo la fase intermedia) que cumple con la posibilidad de oponerse al cierre correcto de la instrucción. Más en extenso ORMAZÁBAL SÁNCHEZ, G, "El periodo intermedio del proceso penal", McGrawn Hill, 1997, p. 137ss.

56 Archivo o sobreseimiento; remisión a falta; o remisión a menores.

57 ORTELLS RAMOS, M, "Problemas de contenido y delimitación de las fases del procedimiento abreviado (diligencias previas, fase intermedia y juicio oral), RGD, 1993, p. 7209. REVERON PALENZUELA, "La contradicción procesal como garantía del derecho de defensa en la llamada fase intermedia del proceso penal por delito", La Ley, ns 4272-4573, de 29 y 30 de junio de 1998 y GASCON INCHAUSTI, F, "La reforma de la Ley de Enjuiciamiento Criminal: Comentario a la Ley 38/2002 y a la Ley Orgánica 8/2002, de 24 de octubre (con Aguilera Morales), Thomson/Cívitas, Madrid, 2003, p. 118

58 Apela la repetida sentencia a una finalidad propia de la fase intermedia en el abreviado consistente en elaborar el "juicio de acusación" posibilitando que las acusaciones formulen sus acusaciones, petición de sobreseimiento o, excepcionalmente la solicitud de ulteriores diligencias (STC 54/91 recogiendo punto por punto la doctrina de la STC 186/1990). La STC 86/1990 atribuye a la fase intermedia en el proceso ordinario una finalidad de revisión de la actividad instructora, finalidad que en el abreviado no existe y de ahí que no importe que el imputado pueda intervenir o no solicitando diligencias complementarias en el abreviado.

59 ORMAZÁBAL SÁNCHEZ, G. "El periodo...”cit. p. 142.

60 La vinculación absoluta del juez a la petición de diligencias complementarias cuando ésta proviene del fiscal ha sido discutida. Valga a título de ejemplo el Auto de la AP de Barcelona, de 3 de Enero de 2001 donde se afirma "No compartimos, en modo alguno, el aserto del Ministerio Fiscal sobre «la juez no puede entrar a 


\subsection{La reforma de la Ley de Enjuiciamiento Criminal, de 24 de octubre de 2002.}

La reforma parcial de la Ley de Enjuiciamiento Criminal de 2002 procuró atender a diversas insuficiencias detectadas, como la necesidad de adquirir la condición de imputado antes de formular acusación ${ }^{61}$, pero a la vez afrontó decididamente resolver las disfunciones señaladas en la materia que nos ocupa.

El Borrador y la Proposición de Ley presentados al Congreso daban entrada al imputado con plenitud de derechos en la fase intermedia a la par que eliminaban ciertas prerrogativas del Ministerio Fiscal en la misma.

La configuración propuesta propiciaba que la decisión sobre el sobreseimiento o la apertura del juicio oral fuera adoptada tras oír las alegaciones del imputado en torno al resultado de la instrucción, con el claro objetivo de adelantar a ésta fase la igualdad de trato de las partes, dando entrada a la defensa ${ }^{62}$. En tal dirección, se preveía que el auto de apertura del juicio oral se dictara una vez efectuado el preceptivo traslado al imputado para alegaciones sobre la procedencia de tal apertura, o sobreseer, tras la eventualidad de que se hubieran pedido la práctica de diligencias complementarias para fundar el ejercicio de la acción ${ }^{63}$. Dicho auto era

valorar la necesidad o no de la diligencias interesada por el M. Fiscal en esta fase intermedia por riguroso imperativo legal». Sin perjuicio del refuerzo que el procedimiento abreviado hace del principio acusatorio, la verdad incuestionable es que todavía el juez de instrucción es el director del proceso y es responsable último de los derechos y garantías de los que son parte. Así, no es acertada la pretensión de que en este proceso hay una fase (la intermedia) en la que una de las partes, singularmente el Ministerio Fiscal puede solicitar cualquier diligencia e indefectiblemente el Juez la deberá practicar."

61 Sobre la necesidad de esta garantía como parte del derecho de defensa se había pronunciado el Tribunal Constitucional en diversas resoluciones: SSTC 135/1989; y 186/1990, así como de presupuesto de la acusación: SSTC 128/1993; 129/1993 y 152/1993.

62 GASCON INCHAUSTI, F (con AGUILERA MORALES, M) "La reforma de la Ley de Enjuciamiento Criminal: Comentario a la Ley 38/2002 y a la LO 8/2002, de 24 de octubre", Civitas, Madrid, 2003. p. 118.

63 El art. 783 de la Proposición de Ley 122/000199 (VII Legislatura, BOC, Serie B, núm 223-1) señalaba: Cuando el Ministerio Fiscal o la acusación particular hayan solicitado la practica de diligencias complementarias o la apertura del juicio oral, se dará traslado de las diligencias previas y de los escritos presentado por el imputado, al que se le emplazará para que en el plazo de tres días comparezcan en la causa con el Abogado que le defienda y Procurador que le represente. Cumplido este trámite, se le emplazará por diez días para realice alegaciones sobre los extremos indicados en el art. 780. Aun en el caso de que se hubiere planteado solicitud de diligencias complementarias, la defensa realizará alegaciones sobre si considera procedente el sobreseimiento o la apertura del juicio oral. Si la defensa acepta la petición de apertura de juicio oral, presentará simultáneamente escrito de defensa. 2. Cuando se haya solicitado la práctica de diligencias complementarias, el juez acordará lo que estime procedente. En todo caso, se citará para su práctica al Ministerio Fiscal y a las partes personadas, dándose nuevo traslado de las actuaciones. 3. Solicitada la apertura del juicio oral por el MF o la acusación particular, el Juez de Instrucción la acordará, salvo que estimare que procede el sobreseimiento, en cuyo caso acordará el que corresponda conforme a los artículos 637 y 641. 4. Al acordar la apertura del juicio oral, resolverá el Juez de Instrucción sobre la adopción, modificación, suspensión o revocación de las medidas interesadas por el MF o la acusación particular, tanto 
Juicio de acusación, imparcialidad del acusador

y derecho de defensa

susceptible de recurso, en tanto el de transformación, regulado en el art. 779.2 LECrim, se declaraba expresamente irrecurrible, como contrapartida y en aras de una inexcusable economía procesal. El imputado no podía recurrir contra el auto de transformación, pero al intervenir en la fase intermedia contaba con todos los elementos para impugnar el auto de apertura del juicio oral, auto que no se olvide le hubiera situado literalmente en la fase de enjuiciamiento sin trámite legal de oposición previa ${ }^{64}$.

Diferentes enmiendas en el Congreso y posteriormente en el Senado, así como una enmienda transaccional aprobada en Comisión eliminó la referencia al recurso contra la resolución de apertura del juicio oral, reintroduciéndolo contra el auto que resuelve continuar el procedimiento al final de la fase instructora, retomando el régimen contemplado en el art. 766 LECrim, o lo que es equivalente, permitiendo el recurso de apelación contra el repetido auto, previa interposición potestativa del recurso de reforma ${ }^{65}$.

La regulación legal resultante se hace así acreedora de las críticas que ya se formularon a los arts. 789 y 790 ALECrim y a la doctrina jurisprudencial que declaró su adecuación a la Constitución, excepto en aquellas materias concretas mejoradas por la reforma de 2002, singularmente la relativa a la imputación, imprescindible para la construcción jurídica que sostiene la STC 186/1990, y que hoy queda plenamente salvaguardada por los artículos 775 y 779.1.4 $4^{\mathrm{a}}$ LECrim.

en relación con el acusado como respecto de los responsables civiles, a quienes en su caso exigirá fianza, si no la prestare el acusado en el plazo que se le señala, así como sobre el alzamiento de las medidas adoptadas frente a quienes no hubieren sido acusados. En el mismo auto señalará el Juez de Instrucción el órgano competente para el conocimiento y fallo de la causa.

$64 \quad$ El art. 783.4 del citado Proyecto omitía la prohibición expresa contra el auto de apertura del juicio oral, lo que permitía interponer contra el mismo recurso de apelación con o sin previa reposición (art. 766 LECrim). Por otra parte, los argumentos esgrimidos para rechazar la reforma por parte del Consejo General del Poder Judicial en su Informe al Proyecto de Ley (Pleno de 8 de abril de 2002) sosteniendo que la falta de recurso limitaba el derecho de las acusaciones a poder instar por la vía del recurso la llamada al procedimiento de otros imputados que no hubieran sido citados en la instrucción y que sólo podrían ser incluidos, tras la recopilación del material probatorio, así como similar limitación del derecho de defensa al no poder solicitar, entonces, ante la Audiencia Provincial el archivo o sobreseimiento provisional; pierden su fundamento sin tenemos en cuenta que esta posibilidad se traslada al final de la fase intermedia, lo que, si bien puede valorarse como una prolongación de la "pena de banquillo" que algunos confieren a la instrucción del proceso (en éste sentido, léase la Enmienda ${ }^{\circ}$ 113 del Grupo Socialista al texto del art. 780 LECrim), presenta la ventaja de que el imputado haya ampliado su información y pueda solicitar el sobreseimiento no ante la Audiencia sino ante el juez de instrucción al que corresponde adoptarlo. VILLAMARIN, M.L. "El sobreseimiento provisional en el proceso penal", Madrid, 2003.

65 La enmienda 150 del Grupo Popular en el Senado reintrodujo la impugnación contra la resolución del Juez de Instrucción de continuar las diligencias previas y argumentando que así se articulaba la contradicción entre las partes, haciéndola innecesaria hasta la apertura del juicio oral. La enmienda transaccional recogía las enmiendas de IU (8); CC (37); PNV (55) GM (81); PSOE (112) (Diario de Sesiones del Congreso de los Diputados, $n^{\circ}$. 259). 
Pervive, sin embargo, una clara desigualdad y una obvia limitación de la contradicción en la fase intermedia del procedimiento abreviado, que no encuentra fundamento coherente ni en apelaciones al sistema acusatorio, entendido este como el referente adversarial, ni en su versión mixta continental ${ }^{66}$. Se trata, de otra manera, de reforzar la oficialidad de la acción penal, y si bien tal tendencia corresponde a la modalidad continental mixta citada, choca frontalmente con la versión más ortodoxa o pura a la que se dice querer tender.

Que en el procedimiento abreviado el juicio de acusación se oriente al juicio sobre la acusación de manera que sólo deban participar quienes tienen atribuido tal cometido; y en esta sede, que las diligencias que puedan solicitarse y practicarse sólo operen en aquella dirección, conduciendo, además, a que la petición de que estas se practiquen vincule sólo si es el órgano oficial de la acusación quien lo hace, resulta una configuración ciertamente más oficialista, pero no más adecuada a un sistema acusatorio. Cierto que el fiscal sería quien instruyera, siempre y cuando se halle la fórmula para garantizar su imparcialidad a la hora de acusar, o en el peor de los casos se prescinda llanamente de esta garantía. Ahora bien, situados ya en el juicio de acusación, o bien se oficializa del todo la acción, eliminando otros posibles acusadores -y no cabe olvidar determinados limites constitucionales- o lo realmente "adversarial" es la igualdad de armas entre acusador y acusado y por supuesto entre acusadores entre $\mathbf{s i}^{67}$.

Y en lo relativo a la posición del imputado, se ha perdido la ocasión de trasladar a esta fase la contradicción, propiciando la intervención del imputado para poder denunciar en su caso posibles inadecuaciones entre los hechos objeto de la instrucción y los que son objeto de la acusación. Claro que el imputado puede estar presente en la práctica de las diligencias complementarias, en virtud de la notificación que prescribe el art. 780,2,III LECrim, pero sin poder de iniciativa en defensa de sus intereses e incluso de los más generales de evitar un proceso innecesario si de las solicitud del imputado se deriva la ausencia de necesidad del juicio oral, denunciando acusaciones extemporáneas o sorpresivas sobre cuyos hechos no se hubiera formulado imputación; falta de tipicidad de los hechos acusados o la prescripción del delito $^{68}$. Para terminar, nótese que esta opción legislativa se aparta de los modelos de derecho comparados utilizados como referentes, singularmente los europeos ${ }^{69}$.

Crítica la misma ORTEGO PEREZ, F, "El juicio de acusación y la proyectada reforma del enjuiciamiento criminal" en R.P.J, n ${ }^{\circ} .69$, 1er trim, 2003, pp.15-16.

67 Vid. El reciente trabajo de GOMEZ COLOMER, J.L., "Adversarial System, proceso acusatorio y principio acusatorio: Una reflexión sobre el modelo de enjuiciamiento criminal aplicado en los Estados Unidos de Norteamérica", Rev. del Poder Judicial, $\mathrm{n}^{\circ}$ especial (Propuestas para una nueva Ley de Enjuiciamiento Criminal), XIX, 2006, pp. 25-77.

68 VERGER GRAU, J. "La defensa del imputado y el principio acusatorio", Bosch, Barcelona, 1994; p. 103.

69 Italia (udienza preliminares); Francia (Chambre d'accusation); Alemania (Zwischenverfharen); Portugal (instruçao), cuya nota común es garantizar la contradicción y con él el derecho de defensa. 


\section{A modo de reflexión final}

Tras este breve examen podría afirmarse que desde diferentes puntos de partida, los países del "common law", aquellos más cercanos a un sistema acusatorio puro y los llamados continentales, donde impera un acusatorio formal con diversas variantes, acometen el cierre de la investigación (constituya o no una fase diferenciada del proceso) y la apertura del juicio, ejercitando la acusación, desde diversas perspectivas que no obstante confluyen en salvaguardar garantías como la imparcialidad y el derecho de defensa.

Ello no obstante, el objetivo se separa, parcialmente, a la hora de diseñar la fase que concluye con el ejercicio de la acción, sus sujetos, las facultades revisoras judiciales y su objeto. En tanto la actividad revisora del ejercicio de la acusación en países como Inglaterra y EEUU de Norteamérica, se orienta no sólo a que el fundamento, los elementos investigadores en que se basa, hayan sido obtenidos legalmente, sino, además, hacia una ponderación sobre las futuras posibilidades de éxito del juicio; en los países continentales, éste último aspecto no es objeto de un interés prioritario, centrando la atención en la garantía de imparcialidad de quienes la conducen y en que el interés público en la persecución garantice la efectiva realización del derecho penal ("nulla poena sine iudicio"). En cuanto al control de la legalidad del quehacer policial, deberá ser tanto más intenso cuanto mas alejada haya estado la investigación de dirección y garantía jurisdiccional. La atención al derecho de defensa no aparece en los primeros hasta tanto se llegue a la primera comparecencia judicial, mientras que en los países del "civil law", la jurisdiccionalización de la investigación y el progresivo traslado de garantías del juicio a la citada fase conducen a adelantar la intervención del imputado a ésta de forma mayoritaria.

Sucede así, que junto a la innegable influencia del modelo acusatorio "puro"70, en sucesivas reformas, singularmente en la italiana y en las de algunos países de Sudamérica ${ }^{71}$; éste se cuestiona, prefiriendo mantener las garantías alcanzadas tras el Antiguo Régimen (especialmente referidas a la contradicción y el derecho de defensa) y extenderlas a las fases de investigación e intermedia, aún a riesgo de arrostrar determinadas críticas que suelen girar en torno a valoraciones como "inquisitorial" o "apartadas de las tendencias internacionales".

En este contexto las líneas precedentes buscan simplemente suscitar la reflexión en torno a una serie de cuestiones comunes detectadas, cuales son: La imparcialidad del fiscal en el desarrollo de la fase investigadora en relación con el juicio de acusación, garantizada en los países donde se conserva la instrucción judicial pero que reclama la incorporación de un "juez de garantías" donde dicha instrucción es competencia del fiscal; y la participación del imputado

\footnotetext{
Mejor adversarial con atemperaciones

América central y del sur está siendo objeto de reformas de hondo calado (Chile, 16 de junio de 2005; Honduras, 20 febrero 2002; Nicaragua, 24 de diciembre 2004; y Colombia (2004 en vigor a partir de 2005).
} 
en el juicio de acusación, con mayor o menor alcance, según se configure el proceso de una forma más o menos adversarial (de partes) u oficial (del órgano que ejerce la acusación oficialmente), ya que en el primero, la máxima acusatoriedad genera una desigualdad en perjuicio del imputado, paliada en los sistemas mixtos por la intervención y ejercicio de facultades revisoras del juez de instrucción o de garantías.

Sobre la imparcialidad del acusador, cabe recordar que una de las conclusiones de la "Comisión Truché" se centra paladinamente en entender que hoy en día el verdadero peligro para las garantías constitucionales del ciudadano subyace en el equilibrio entre la instrucción y la acusación, más que en la separación entre acusación y juicio, así como en la protección de los derechos del acusado, de manera que el órgano acusador no pueda adoptar determinadas medidas que arrojen una carga excesiva de parcialidad, poniendo de relieve la falta de distanciamiento psicológico de quien habiendo conducido la investigación deben luego sostener la acusación. El peligro surge en tal caso porque los rasgos inquisitorios se trasladan al fiscal corriendo el riesgo de arbitrariedades en la investigación y de invasión indebida de la vida privada $^{72}$.

En cuanto a la fase intermedia, denominada en ocasiones "juicio de acusación", hay que afrontar seriamente si existen razones de peso suficientes como para excluir la salvaguarda en la misma del principio de contradicción y del derecho de defensa, atendiendo por ejemplo al referente que constituye el reformado proceso penal italiano -del que por cierto existe acuerdo en admitir constituye la aproximación más decidida hacia el modelo adversarial de los EEUU de Norteamérica- extrayendo las lecciones correspondientes de sus más de diez años de vigencia. Entre ellas: la notable desigualdad entre las partes que se crea en los sistemas del "common law", como consecuencia de eliminar la fase investigadora; desigualdades, que desaparecen o se ven notablemente paliadas en los procesos penales mixtos, en los que la intervención judicial opera como garante a través de un amplio abanico de cuestiones: revisando el quehacer policial o de la fiscalía en la investigación; por su imprescindible intervención para limitar determinados derechos; o, realizando funciones de arbitro imparcial entre acusación y defensa.

Los intentos armonizadores del "Corpus Iuris" y Libro Verde sirven para acrisolar las citadas aseveraciones, que pueden completarse con las siguientes: a) No hay que olvidar las tensiones entre los diferentes poderes, singularmente el ejecutivo y el judicial, a la hora de configurar el ejercicio de la acción penal, prioritariamente en su faceta de "poder de acusar" y el mayor o menor control judicial que pueda ejercerse sobre el mismo. Expresado en otros

72 Informe de la Comisión de Reflexión sobre la Justicia”, elaborado en Francia en 1977, que recibe el nombre del presidente de la corte de Casación al que se encomendó su presidencia. Recuérdese que Francia encomendó la instrucción al fiscal en la reforma de Enero de 1993 (inspirada en el Informe Delmas Mary) retornado al modelo previo de instrucción judicial en agosto del mismo año. 
Juicio de acusación, imparcialidad del acusador

y derecho de defensa

términos: las tensiones y mecanismos de contrapesos a la hora de acusar y controlar dicha acusación han de contemplar una doble perspectiva, según exista mayor o menor ámbito de discrecionalidad a la hora de ejercitar la repetida acción penal; y se prevea una mayor o menor amplitud en la revisión judicial de ese ejercicio; y b) Deben salvaguardarse las garantías del ciudadano, encomendadas a un órgano judicial, ex ante (en los casos en que se establece su necesaria intervención en la adopción de determinadas medidas), o ex post, cuando a falta del citado control, revise lo actuado a efectos de fundar la acusación.

El modelo procesal de la Corte Penal Internacional y el CCP italiano abre o sugiere otras reflexiones en torno al sistema adversarial o de partes cuando se advierte: a) que el pretendido señorío sobre la acusación del fiscal puede quedar sometido a férreo control jurisdiccional cuando intereses de la persecución así lo aconsejen, como lleva a cabo la Sala de Cuestiones Preliminares de la Corte Penal Internacional, sin que se aprecie reminiscencias inquisitoriales o manifestación de tendencia alguna hacia un sistema mixto; y b) que como los más de diez años de vigencia del CPP italiano han puesto de manifiesto, la mayor aproximación a un sistema acusatorio "puro", entendido como adversarial, acarrea notables desigualdades entre la acusación y el imputado, ahondadas cuando aquella se ejerce en régimen de monopolio. Y todo, sin olvidar el hecho de que la etapa intermedia (udienza preliminare) se realiza salvaguardando la audiencia al acusado y la contradicción.

Cabría terminar estas líneas recordando algunos asertos, que aunque conocidos, al haber sido de objeto de dudas o confusiones, debieran ser objeto de previo acuerdo ante cualquier iniciativa legislativa: a) los sistemas adversarial y acusatorio no son términos equiparables; b) el sistema adversarial pone de manifiesto incompatibilidades difíciles de superar con la oficialidad de la acción penal y la igualdad entre las partes; c) el sistema adversarial limita considerablemente el derecho de defensa en la fase intermedia, precisamente por obedecer a una configuración general diferente de la investigación y el ejercicio de la acción. Si, finalmente, el objetivo último final de la reforma de la Ley de Enjuiciamiento Criminal no es articular un sistema adversarial sino uno acusatorio y ambos no son equivalentes, cabría evaluar bien las constantes apelaciones a modelos adversariales, cuando realmente se incorporan novedades que se cohonestan con un "proceso de partes", pero que no resultan consustanciales en modo alguno a la "mayor acusatoriedad del sistema".

En todo caso, y aun sin negar la influencia de la internacionalización de la justicia, que en buena medida es admitir el influjo determinante del sistema de los EEUU de Norteamérica, no conviene preterir, que aún así, muchos modelos europeos se apartan o al menos modulan éste último, preservando un buen equilibrio entre la balanza de la eficacia y la merma de garantías, evitando de este modo, que ceda única o predominantemente la relativa al derecho de defensa, especialmente en las fases instructora e intermedia en donde muchos ordenamientos europeos -con las reservas señaladas respecto de nuestro proceso abreviado- ofrecen un panorama notablemente más garantista. 